\title{
Enhancer-trap targeting at the Broad-Complex locus of Drosophila melanogaster
}

\author{
Geneviève Gonzy-Tréboul, Jean-Antoine Lepesant, and Jean Deutsch ${ }^{1,2}$ \\ Laboratoire de Biologie du Développement, Institut Jacques Monod, Centre National de la Recherche Scientifique (CNRS) \\ et Université Paris 7-Denis Diderot, 75251 Paris CEDEX 05, France
}

Here, we describe the exact replacement of a defective unmarked $P$ element by an enhancer-trap transposon marked by the miniwhite gene and carrying $l a c Z$ as a reporter gene. The original defective $P$ element was located in an intron of the Broad-Complex (BRC), a key gene involved in metamorphosis. Replacement events resulted from conversions induced by the P-element transposase from a donor enhancer-trap element located on another chromosome. Six independent conversion events were selected. In all converted chromosomes, the enhancer-trap transposon was in the same orientation as the original $P$ element. From the pattern of $X$-gal staining observed, lacZ expression likely reflects the regulatory influence of $B R C$ enhancers on the convertant transposon. Reversion to wild type was achieved by excision of the enhancer-trap transposon. The six convertants were analyzed in detail at the nucleotide level. The occurrence of a polymorphism at position 33 of the P-element sequences led us to propose a conversion mechanism involving homologous $P$ sequences for repair. This is in contrast to previously analyzed P-element transposase-induced conversion events and proposed models relying on sequence identity between genomic Drosophila sequences. The lack of any homology requirement other than between $P$ element sequences means that our findings can be easily generalized. Targeting a marked P-element derivative at a precise site without loss or addition of genetic information makes it possible to exploit the hundreds of defective $P$ elements scattered throughout the Drosophila genome by replacing them with engineered $P$ elements, already available.

[Key Words: Enhancer-trap; P element; conversion; homologous recombination; Broad-Complex; Drosophila]

Received November 14, 1994; revised version accepted March 23, 1995

For $\sim 12$ years, P-element derivatives have been used extensively as vectors for germ-line transformation (Rubin and Spradling 1982) and enhancer trapping (O'Kane and Gehring 1987). Unlike yeast molecular genetics with its system of transformation and mouse molecular genetics with its system of transgenesis, Drosophila molecular genetics suffers from the lack of a genetic system that permits easy selection of homologous recombination events. In vitro-engineered $P$ elements containing Drosophila sequences do not reach the original genomic site of these sequences but, rather, insert at any location in the genome, although some homing effects, not fully understood yet, have been reported in certain conditions (Fauvarque and Dura 1993; Hama et al. 1990). This random insertion of $\mathrm{P}$ elements generates position effects that result from unrelated flanking sequences. The development of enhancer-detector elements turned this drawback into an advantage (for review, see Wilson et al. 1990|. In these elements, a lacZ reporter gene is fused to

\footnotetext{
${ }^{1}$ Present address : Evolution Moléculaire, Université Pierre et Marie Curie, Bat B, 707, 75252 Paris CEDEX 05, France.

${ }^{2}$ Corresponding author.
}

a weak Drosophila-compatible promoter, the P element promoter itself. Insertion of the enhancer-detector element near flanking Drosophila genomic enhancers can activate this promoter, thus allowing the screening of insertions of $\mathrm{P}$ elements according to the pattern of expression of a nearby gene, even when the insertion itself does not lead to any phenotype. A huge number of enhancer-trap transgenic lines has been produced, allowing molecular and genetic analysis of many new genes.

Engels and co-workers made a breakthrough in the use of homologous recombination as a tool for reverse genetics in Drosophila when they showed that the P-element transposase was able to induce conversion of Drosophila sequences. In their experiments, requirements for conversion, besides a source of P-element transposase, were (1) the presence of a P element at the converted acceptor site; and (2) the presence of donor Drosophila sequences homologous to the region of the acceptor site at an ectopic locus, introduced by means of a P transgene, (Engels et al. 1990, 1994; Gloor et al. 1991; Johnson-Schlitz and Engels 1993).

Here, we report a new development of P-element transposase-induced conversion: site-directed enhancer 
trapping. As mentioned above, the enhancer-trap device makes it very easy to describe the developmental pattern of expression of a gene. The potential use of this method would be greatly enhanced if the enhancer-trap transposon could be targeted to a chosen genomic site.

We chose the Broad-Complex $(B R C)$ as a model system. Several investigators have shown that the $B R C$ corresponds to one of the early genes (Ashburner et al. 1974) involved in the modulation of the hormonal response during the third stage of larval development (for review, see Andres and Thummel 1992). Molecular analysis has revealed that it comprises a single gene extending over $100 \mathrm{~kb}$, giving rise to a large number of transcripts. The transcripts known to date can be classified into four families: Each family possesses a single alternative $3^{\prime}$ exon coding for a pair of zinc finger motifs, Z1, Z2, Z3, and Z4 (DiBello et al. 1991, C. Bayer, pers. comm.) (see a simplified molecular map on Fig. 1). Although P/M dysgenesis-induced mutants have been isolated (Belyaeva et al. 1989), so far no enhancer-trap insertion has been located at the $B R C$. Such a tool could help to describe the pattern of expression of this complex gene and to analyze its genetic functions.

We obtained, at a manageable frequency, targeting of an enhancer-trap element to a P-defective element inserted in an intron of the $B R C$. We analyzed six independent mutants at the nucleotide level and report molecular evidence to support that their occurrence is the result of conversion events. The main difference between these conversion events and those analyzed by Engels and co-workers (Engels et al. 1990; Gloor et al. 1991) is that no homology was required between donor sequences and genomic Drosophila sequences at the acceptor site of the conversion: The sole homology was between $\mathrm{P}$ sequences themselves. Despite this striking difference, our results, with minor modifications, are in agreement with Engels' model for P-element transposase-induced conversion.

\section{Results}

Genetic and molecular analysis of the p14 mutant

The initial $B R C$ allele used in this work, known previ- ously as $1(1) 2 B c^{l p 14}$ (Sampedro et al. 1989) or $1(1) 2 B c^{5}$ (Lindsley and Zimm 1992), is hereafter designated as p14. It was originally selected as a viable mutant unable to complement a deficiency that encompassed the $B R C$ in a classic $\mathrm{P} / \mathrm{M}$ dysgenesis mutagenesis screen with the $\pi 2$ strain (Solovyeva and Belyaeva 1989). Southern blotting and in situ hybridization on polytene chromosomes revealed that the original $\mathrm{X}$ chromosome (from a strain kindly provided by I. Zhimulev and E. Belyaeva) contained, in addition to a $\mathrm{P}$ element inserted at the $2 \mathrm{~B} 5$ location of the $B R C$, three other P elements scattered at various locations along the $\mathrm{X}$ chromosome. Therefore, we generated a $p 14, w^{67 c 23}$ recombinant chromosome and checked, by both Southern blotting and in situ hybridization, that it contained a single P element located at 2B5. Strains carrying this chromosome were used in all of the following experiments.

Starting with this purified chromosome, we confirmed and extended prior genetic and molecular analyses of the p14 allele (Belyaeva et al. 1989; Sampedro et al. 1989). The $B R C$ presents a genetic structure as complex as its molecular one: Four independent complementation groups have been described, namely $b r, r b p, 2 B c$, and $2 B d$. In addition, two overlapping complementation groups are known: npr, which overlaps all four previously mentioned groups; and $2 B a b$, which overlaps $b r$ and $r b p$ only (Kiss et al. 1988; Belyaeva et al. 1989). The p14 mutant is homozygous and hemizygous viable and does not exhibit any typical $B R C$ phenotype. The $p 14$ allele is lethal over deficiencies uncovering the $B R C$ and over npr amorphic alleles and can thus be classified as a bona fide $B R C$ allele. It did, however, complement strong alleles belonging to the three complementation groups, $b r$, $r b p$, and $2 B c$, as well as the unique hypomorphic allele of the fourth group 2Bd (Table 1). Hence, it could not be assigned with certainty to any one of the known complementation groups.

The pl4 chromosome was shown previously to contain a P element located at the $B R C$ locus (Sampedro et al. 1989) around coordinate 172 of the standard molecular map of the locus (Chao and Guild 1986) (Fig. 1). By Southern analysis and polymerase chain reaction (PCR) amplification with primers complementary to the 31 -bp

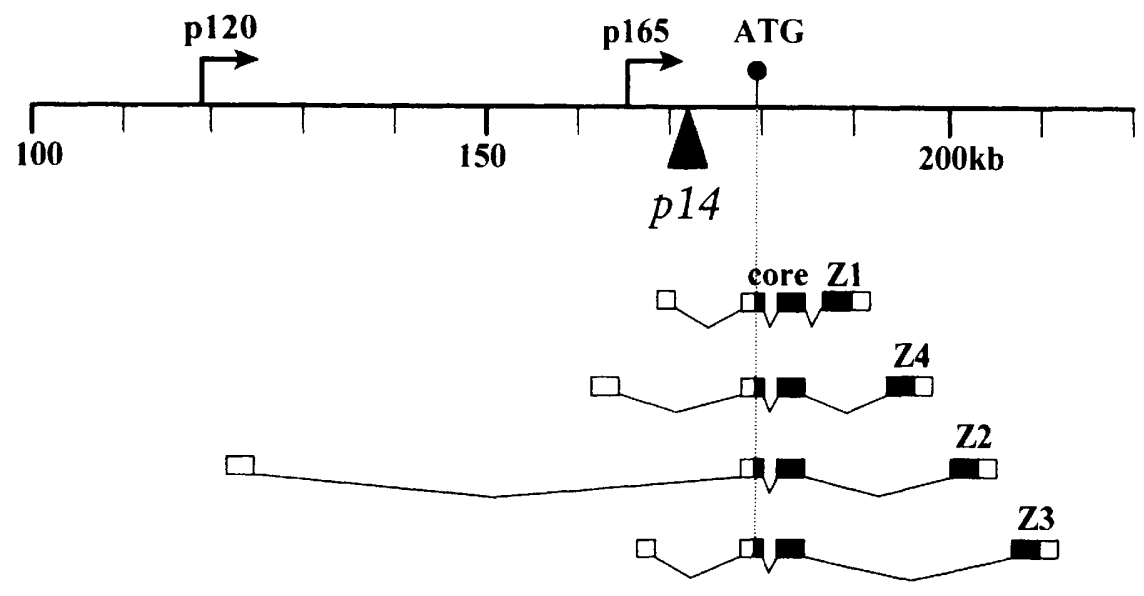

Figure 1. A simplified molecular map of the $B R C$ locus [adapted from DiBello et al. (1991) and C. Bayer (pers. comm.). Two identified promoters are indicated, at positions 120 and 165 of the molecular map (Chao and Guild 1986). Only the major forms of messages are drawn. (Solid boxes) Translated regions; (open boxes) untranslated regions. $(Z 1-Z 4)$ Pairs of zinc finger motifs. The insertion point of the pl4 $\mathrm{P}$ element is indicated by a solid triangle. 
Table 1. Genetic analysis of $P[Z w]$ mutants

\begin{tabular}{|c|c|c|c|c|c|c|c|c|c|c|}
\hline Mutants & Eye color & $\begin{array}{l}\text { Stage of } \\
\text { lethality }\end{array}$ & $n p r^{6}$ & $b r^{28}$ & $r b p^{5}$ & $2 B c^{2}$ & p14 & $2 B d^{I}$ & $2 B a b^{5}$ & $D f(1) S 39$ \\
\hline p14 & white & viable & $0 / 48$ & $108 / 75$ & $52 / 29$ & $17 / 12^{\mathrm{a}}$ & & $86 / 79$ & & \\
\hline M1 & orange & prepupal & $0 / 43$ & $0 / 66$ & $1 / 75$ & $\begin{array}{l}90 / 66^{\mathrm{b}} \\
(1.36)\end{array}$ & $\begin{array}{c}120 / 151^{c} \\
(0.79)\end{array}$ & $\begin{array}{c}99 / 79 \\
(1.2)\end{array}$ & $0 / 67$ & $0 / 72$ \\
\hline M2 & orange & prepupal & $0 / 146$ & $2 / 113$ & $0 / 147$ & $\begin{array}{l}61 / 80 \\
(0.76)\end{array}$ & $\begin{array}{r}89 / 95^{c} \\
(0.94)\end{array}$ & & & \\
\hline M3 & orange & prepupal & $0 / 41$ & $2 / 66$ & $1 / 61$ & $\begin{array}{l}47 / 63 \\
(0.75)\end{array}$ & $\begin{array}{l}58 / 59^{c} \\
(0.98)\end{array}$ & & & \\
\hline M4 & bright red & prepupal & $0 / 38$ & $0 / 53$ & $0 / 24$ & $\begin{array}{c}28 / 38 \\
(0.74)\end{array}$ & $\begin{array}{c}39 / 104^{c} \\
(0.37)\end{array}$ & & & \\
\hline M5 & deep orange & prepupal & $0 / 54$ & $1 / 47$ & $0 / 50$ & $\begin{array}{c}29 / 60 \\
(0.48 \mid\end{array}$ & $\begin{array}{l}74 / 86^{c} \\
(0.86)\end{array}$ & & & \\
\hline M6 & orange & prepupal & $0 / 42$ & $0 / 53$ & $1 / 66$ & $\begin{array}{l}41 / 89 \\
(0.46)\end{array}$ & $\begin{array}{c}82 / 123^{c} \\
(0.67)\end{array}$ & & & \\
\hline M7 & orange & prepupal & $0 / 64$ & $0 / 33$ & $0 / 49$ & $\begin{array}{c}49 / 63 \\
(0.78)\end{array}$ & $\begin{array}{l}47 / 92 \\
(0.51)\end{array}$ & & & \\
\hline M8 & orange & third larval & $0 / 123$ & $0 / 101$ & $0 / 153$ & $0 / 118$ & $\begin{array}{l}5 / 104^{d} \\
(0.05)\end{array}$ & & & \\
\hline
\end{tabular}

Crosses were performed at $25^{\circ} \mathrm{C}$ between mutant males (first column) and females (first line) carrying the indicated $B R C$ allele over the FM6, I(1) balancer as for lethal alleles or homozygous females as for viable alleles (i.e. $p 14$ and $2 B d^{\prime}$ ). The ratios are the number of complementing Bar ${ }^{+}$females over the number of sibling Bar females, except in crosses involving the viable alleles. In this case the ratio is the number of complementing females over the number of sibling males. Crosses performed at $29^{\circ} \mathrm{C}$ gave essentially the same results (not shown).

aFigures from a similar cross with the $2 B c^{l}$ allele: $44 / 50$.

'Figures from a similar cross with the $2 B c^{l}$ allele: $93 / 55$.

' $10 \%$ to $25 \%$ of the complementing females showed malformed third legs.

${ }^{\mathrm{d}}$ All complementing females had malformed third legs.

terminal inverted repeats shared by $\mathrm{P}$ elements, the length of the p14 P element was estimated to be $0.85 \mathrm{~kb}$. It was located precisely within a 565-bp PstI-ClaI fragment (Fig. 2) whose wild-type sequence was determined (Fig. 3). By use of the appropriate primers located within the $P$ element and the flanking genomic sequences (Fig. 3), junction fragments were amplified from the mutant DNA and sequenced. The p14 P element was inserted 399 bp downstream from the PstI site and 166 bp upstream from the Clal site oriented in the same $5^{\prime} \rightarrow 3^{\prime}$ direction as the $B R C$ transcript. An 8-bp ATCTAGCG target sequence was found duplicated on each side of the transposon. Both ends of the p14 P element were complete: $109 \mathrm{bp}$ on the $5^{\prime}$ side and $123 \mathrm{bp}$ on the $3^{\prime}$ side were sequenced and found to be identical to the wild type (O'Hare and Rubin 1983).

The p14 chromosome was subjected to reverse mutagenesis with $\mathrm{P}[\Delta 2-3](99 \mathrm{~B})$ as a source of transposase. Revertants were selected that fully complemented the amorphic $n p r^{\prime}$ allele and exhibited a wild-type molecular pattern within the limits of detection of Southern analysis.

It can be concluded from these results that the defective $\mathrm{P}$ element is responsible for the hypomorphic $p 14$ mutation of the $B R C$. This element is amenable to P-element transposase-induced modifications. It is inserted in a noncoding region, not far downstream from a known promoter. Because the p14 mutant is viable, no extra

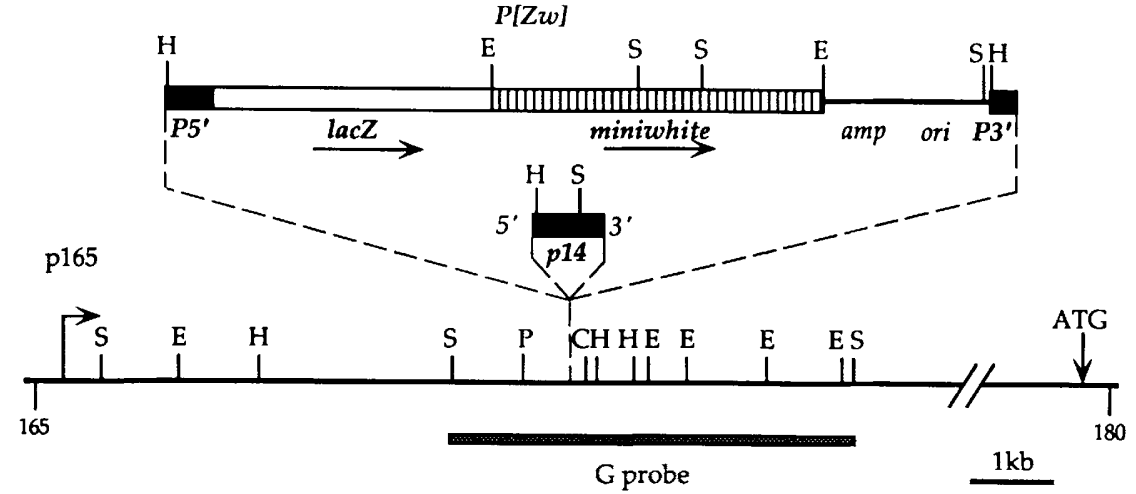

Figure 2. Molecular structure of the p14 and convertant alleles. A restriction map of the genomic sequences of the $B R C$ from coordinates 165 to 180 is shown. The molecular structure of the pl4 and $\mathrm{P}[\mathrm{Zw}]$ elements are drawn above the insertion site. (E) EcoRI; (C) ClaI; (H) HindIII; (Ps) PstI; (S) SalI. (Solid boxes) P-element sequences; (open box) lacZ sequences; (striped box) white sequences; (thin line) plasmid sequences. $(G$ probe) $B R C$ genomic probe used in Southern blots. 
a) restriction map of the $S a I-C l a I$ fragment

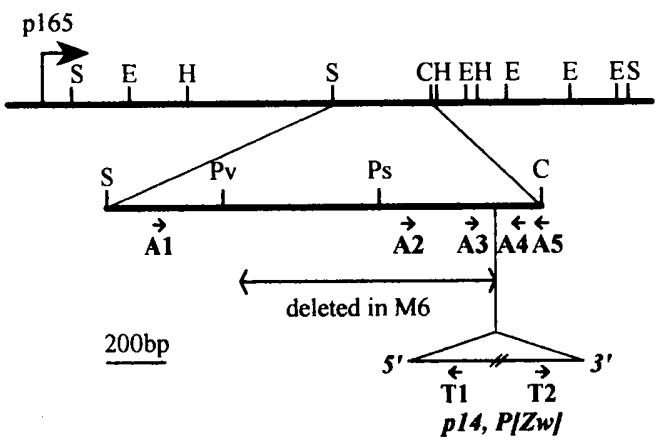

b) partial nucleotide sequence of the Salt-Clal fragment

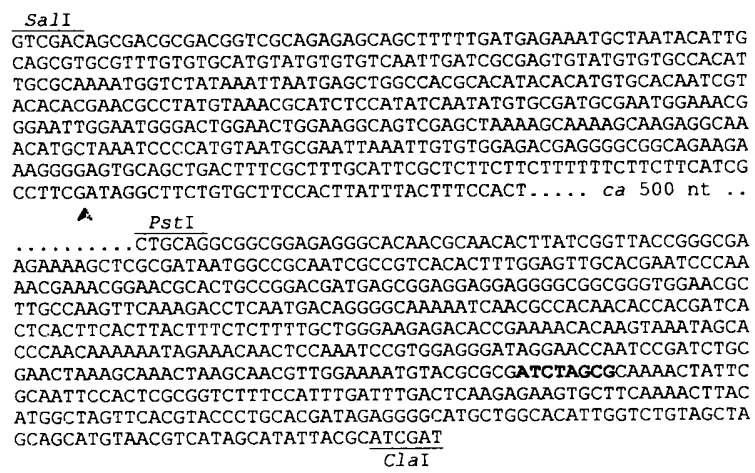

c) sequence of the junctions in the convertants $\downarrow$ in M5, M6

GTACGCGCGATCTAGCGcatgatgaaataacataaggtggtcccgtcga Aagccgaagctt.... $P[2 \mathrm{w}] . \mathrm{ca} 10 \mathrm{~kb}$. . gccgacgggaccaccttatgt tatt tcatcatgATCTAGCGCAAAAC.

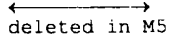

Figure 3. Molecular analysis of the insertion site. (A) A molecular map of the SalI-ClaI fragment of the $B R C$ in which the p14 and convertant elements were inserted. Restriction sites are the same as in Fig. 2, with the addition of PvuII (Pv). (B) Partial nucleotide sequence of this fragment. 462 nucleotides was determined from the SalI site, then $\sim 500$ nucleotides undetermined until the PstI site. The sequence of the PstI-ClaI fragment (565 nucleotides) was determined on both strands. The 8-bp target sequence of the p14 and the $\mathrm{P}[\mathrm{Zw}]$ converted elements is in boldface type. The left breakpoint of the genomic deletion (at nucleotide 425 downstream from the Sall site), associated with the conversion in the $2 B a b^{10}(\mathrm{M} 6)$ allele is indicated by an arrowhead. $(C)$ Nucleotide sequence of the junction between $B R C$ genomic sequences and P-element sequences in the convertants. The $5^{\prime}$ and $3^{\prime}$ junction sequences are given for the $2 B a b^{8}$ allele (mutants M1-M4). The 12 nucleotides deleted at the $3^{\prime}$ end in the $2 B a b^{9}(\mathrm{M} 5)$ allele are indicated. The right breakpoint of the deletion at the $5^{\prime}$ end of the $2 \mathrm{Bab}^{10}(\mathrm{M} 6)$ allele is indicated by an arrowhead. $B R C$ sequences are in uppercase, and the target sequence is in boldface type. P-element sequences are in lowercase; the 31-nucleotide terminal repeats are underlined. The A (in M1-M4) or T (in M5 and M6) nucleotide at position 33 is in italics and uppercase lettering.

wild-type copy of the $B R C$ is needed in the genome. All of these features made the $p 14$ allele a good candidate for the introduction of an enhancer-trap $\mathrm{P}$ element into the $B R C$ locus.

\section{Screening for a targeted enhancer-trap $P$ element}

A strain was constructed carrying the p14 P element on the $\mathrm{X}$ chromosome and an enhancer-trap element, hereafter designated as $\mathrm{P}[\mathrm{Zw}]$, on a Cy-marked second chromosome. Both elements can be mobilized by the presence of transposase. At the $B R C$ locus, the mutagenic events resulting from the mobilization of these transposons may be (1) excision of the original p14 P element leading to either reversion, internal rearrangement, or deletion of flanking genomic sequences; (2) transposition of the $\mathrm{P}[\mathrm{Zw}]$ element, of the p14 P element, or of both; $|3|$ conversion of the p14 P element to the $\mathrm{P}[\mathrm{Zw}]$ element. In addition, both elements may transpose anywhere else in the genome.

We guessed that the replacement of the p14 P element by the $\mathrm{P}[\mathrm{Zw}]$ transposon would lead to a stronger $B R C$ phenotype, such as broad wings, malformed legs, reduced number of bristles on the palpus and sternites, or lethality. Lethality, and mutant phenotypes as well, can be rescued by crossing the progeny from the P-element transposase-induced mutagenesis with white attached-X females carrying on the $\mathrm{Y}$ chromosome a duplication of the tip of the $\mathrm{X}$, including a wild-type copy of the $B R C$ locus.

The mating scheme is described in Figure 4. Five hundred seventy-four independent dysgenic lines were established, from which 544 independent eye-colored nonCurly males were selected for possible transposition for conversion) events affecting the $\mathrm{P}[\mathrm{Zw}]$ element (see $\mathrm{Ma}$ terials and methods). Mutant lines underwent a series of genetic tests: a test for $\mathrm{X}$-linkage of the $\mathrm{P}[\mathrm{Zw}]$ transposon, a test for lethality or a visible phenotype by crossing with an attached-X strain devoid of the duplication, and a test for $B R C$ allelism by complementation testing with the amorphic $n p r^{6}$ allele.

From $155 \mathrm{X}$-linked transposition events, eight independent mutants were recovered, corresponding to lethal mutations in the region covered by the duplication. All turned out to be $B R C$ mutants. No viable $B R C$ mutants were recovered. The genetic analysis of these eight lethal mutants is detailed in Table 1. One mutant (M8) is lethal at the third larval stage, does not complement alleles from any of the three complementation groups, $b r, r b p$, and $2 B c$, and therefore belongs to the npr complementation group. The seven other mutants are lethal at the prepupal stage, complement $2 B c$ alleles but not $b r$ nor $r b p$ ones, and thus belong to the $2 \mathrm{Bab}$ partially noncomplementing group.

\section{Molecular analysis of the mutants}

DNA from each of the eight mutants was extracted from hemizygous male larvae and from sibling attached-X females, then digested with three different enzymes (EcoRI, HindIII, and SalI). Southern blots were hybridized with probes specific for (1) a 4.8-kb fragment of wild- 


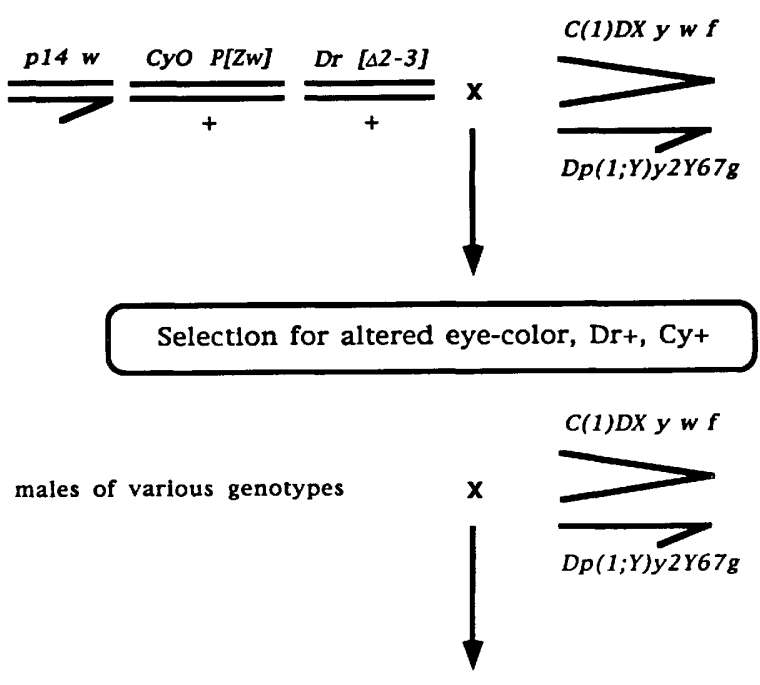

Selection for $\mathrm{X}$-linked $P[Z w]$

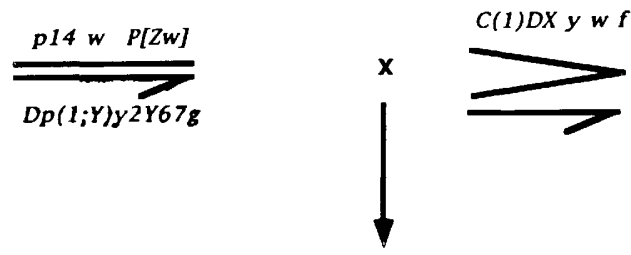

Selection for lethality

Figure 4. Genetic screening of convertants. $G_{0}$ males possess both the target $\mathrm{pl} 4$ and $\mathrm{P}|\mathrm{Zw}|$ transposons and the $\mathrm{P}|\Delta 2-3|$ source of transposase. Among their $G_{1}$ progeny, males with colored eyes and non-Curly wings were selected: They originated from a transposition or conversion event affecting $\mathrm{P}[\mathrm{Zw} \mid$. The second step allows the recovery of $\mathrm{P}|\mathrm{Zw}|$ bearing $\mathrm{X}$ chromosomes. The expected conversion might have occurred among these. At the third step, males were successively crossed first with attached-X females carrying the $y^{2} Y 67 g$ duplication covering the $B R C$, then with females without duplication, to check for lethality.

type $B R C$ sequences encompassing the $p 14$ insertion site (G probe, Fig. 2); (2) the complete P element; and (3) plasmid sequences present in the $\mathrm{P}[\mathrm{Zw}]$ transposon.

In five of the eight mutants (M1-M5, Table 2) a strikingly constant pattern was observed. This pattern strictly corresponded to that expected for the exact replacement, within the limits of a Southern analysis, of the pl4 P element by the $\mathrm{P}[\mathrm{Zw}]$ transposon in the same orientation (Fig. 2). Additional evidence in favor of the integrity of internal $\mathrm{P}[\mathrm{Zw}]$ sequences was the functionality of $1 a c Z$ (as shown by X-gal staining; see below), white (as shown by eye phenotype), and plasmid sequences (as shown by plasmid rescue, see below). We interpret these mutants to result from five independent conversion events. Whatever the actual molecular mechanism, the replacement of a defective $P$ element by an enhancer trap at the same site can be considered to be a conversion. In two of the mutants ( $\mathrm{Ml}$ and $\mathrm{M} 2)$, Southern analysis indicated the presence of a single $P$ element, whereas in the other three (M3-M5), additional bands appeared with the P-element-specific probe. These signals could be easily interpreted as resulting from additional mutagenic events: a p14 X-linked transposition in the M3 mutant, and additional X-linked $\mathrm{P}[\mathrm{Zw}]$ transpositions for the M4 and M5 mutants. By Southern probing, these other P elements were shown to be located outside a 4.8-kb fragment encompassing the pl4 site and were not localized more precisely. A sixth mutant, M6, appeared to be identical to the other convertants at the $3^{\prime}$ junction while differing at the $5^{\prime}$ junction (Fig. 3). We conclude that this mutant resulted from an imperfect conversion associated with a 880 -bp deletion of genomic sequences on the $5^{\prime}$ side.

These six conversions were analyzed at the nucleotide level. From Ml genomic DNA, four different plasmids comprising the $5^{\prime}$ and the $3^{\prime}$ genomic sequences flanking the transposon were rescued. On the $5^{\prime}$ side, $0.4 \mathrm{~kb}$ of genomic sequence was cloned from a Pst digestion and $0.45 \mathrm{~kb}$ from a Bglll digestion. On the $3^{\prime}$ side, $0.55 \mathrm{~kb}$ was cloned from an EcoRI digestion and $3.2 \mathrm{~kb}$ from a SacII one.

These plasmids enabled us to sequence both junctions of the $\mathrm{P}[\mathrm{Zw}]$ element present in the M1 mutant. Genomic sequence $(231,230 \mathrm{bp})$ was determined upstream and downstream of the insertion site, respectively. These sequences were identical to the wild-type $B R C$ sequence, and the same 8-bp target site, as in the pl4 chromosome, was found (Fig. 3b). Thus, in the Ml mutant, the $\mathrm{P}[\mathrm{Zw}]$ element is inserted at exactly the same nucleotide as the original $p 14$. Internal to the transposon, a 303-nucleotide-long sequence identical to the Carnegie vector P-element sequences (Rubin and Spradling 1983) was determined on the $3^{\prime}$ side. It is noteworthy

Table 2. Molecular features of the eight lethal BRC mutants

\begin{tabular}{|c|c|c|c|}
\hline Mutants & $\begin{array}{l}\text { Event at the } \\
\text { p14 site }\end{array}$ & $\begin{array}{l}\text { Nucleotide at } \\
\text { position } 33 \text { of } \\
\text { the P element }\end{array}$ & Other events \\
\hline Ml & conversion & A & \\
\hline M2 & conversion & A & \\
\hline M3 & conversion & A & $\begin{array}{l}\mathrm{X} \text {-linked pl4 } \\
\text { transposition }\end{array}$ \\
\hline M4 & conversion & A & $\begin{array}{l}\text { another X-linked } \\
P[Z w] \text { element }\end{array}$ \\
\hline M5 & $\begin{array}{l}3 \text { ' incomplete } \\
\text { conversion, } \\
\text { 12-bp deletion }\end{array}$ & $\mathrm{T}$ & $\begin{array}{l}\text { another X-linked } \\
\mathrm{P}[\mathrm{Zw}] \text { element }\end{array}$ \\
\hline M6 & $\begin{array}{l}5 \text { ' incomplete } \\
\text { conversion } \\
880 \text {-bp deletion }\end{array}$ & $\mathrm{T}$ & \\
\hline M7 & rearrangement & & $\begin{array}{l}\mathrm{X} \text {-linked } \mathrm{P}[\mathrm{Zw}] \\
\text { element }\end{array}$ \\
\hline M8 & 7.4-kb deletion & & $\begin{array}{l}\mathrm{X} \text {-linked } \mathrm{P}[\mathrm{Zw}] \\
\text { element }\end{array}$ \\
\hline
\end{tabular}


that the HindIII site specific to the $\mathrm{P}[\mathrm{Zw}]$ transposon was found in $\mathrm{Ml}$ at the expected position. Two hundred seventy-five nucleotides of the $P$ element was determined on the $5^{\prime}$ side, and found to be identical to the corresponding wild-type P-element sequences $/ \mathrm{O}^{\prime}$ Hare and Rubin 1983). Significantly, an A was found at position 33 (taking +1 as the first nucleotide of the P-element sequence), as in the $p 14 \mathrm{P}$ element, whereas a $\mathrm{T}$ is present in the original $\mathrm{P}[\mathrm{Zw}]$ at this position (Table 2). The original $\mathrm{P}[\mathrm{Zw}]$ is a derivative of the Carnegie series of vectors that share this single sequence difference from wild-type P elements (Rubin and Spradling 1983). Thus, the $\mathrm{P}[\mathrm{Zw}]$ transposon present at coordinate 172 in the $M 1$ mutant bears, at position 33, a nucleotide specific to the previous pl4 P-element.

The junctions between the inserted transposon and genomic sequences were determined at the nucleotide level in the five other convertants through direct sequencing of PCR amplification products with pairs of P-element-specific and $B R C$-specific primers (Fig. 3). M2 to M4 transposons were found to be identical to Ml (Table 2). The M5 element revealed two peculiarities: At the 5 ' end, although the junction between genomic and P-element sequences was found to be identical to the other mutants, including the 8-bp target sequence, it possessed a $T$ at position 33 of the P-element sequence, typical of a $\mathrm{P}[\mathrm{Zw}]$ element. At the 3 ' end, a small 12-bp deletion was present, which included the last $4 \mathrm{bp}$ of the $\mathrm{P}$ element and the 8 -bp genomic repeat (Table 2 ; Fig. $3 \mathrm{c}$ ).

The breakpoints of the deletion associated with the imperfect conversion of M6 were determined at the nucleotide level. About 880 bp of genomic sequence and 21 bp of P-element sequence were deleted on the $5^{\prime}$ side of the transposon (Figs. 2 and 3). The 5' genomic 8-bp repeat was included within the deletion. A $\mathrm{T}$ nucleotide was found at position 33 of the P-element sequence, indicating a $\mathrm{P}\left[\mathrm{Zw}\right.$ ) origin (Table 2). On the $3^{\prime}$ side, the genomic 8-bp-specific target sequence was conserved, indicating again that this conversion event occurred precisely at the p14 site.

The structure of the last two M7 and M8 mutants was also investigated. In each one a $\mathrm{P}[\mathrm{Zw}]$ transposon was present on the $\mathrm{X}$ chromosome but was located outside a $4.8-\mathrm{kb}$ region encompassing the $p 14$ site. Their $B R C \mathrm{mu}-$ tant phenotype is attributable to an insertion of unrelated sequences $(M 7)$ or a 7 -kb deletion of $B R C$ genomic sequences (M8) at the pl4 site.

\section{Reversion of the $P[\mathrm{ZW}]$ insertion}

Considering that the original p14 mutant was homozygous viable and that the convertants were all lethal, we wondered whether the lethality was attributable only to the presence of the $\mathrm{P}[\mathrm{Zw}]$ transposon at the same site or whether it could be the result of another mutagenic event elsewhere on the $100-\mathrm{kb} B R C$ locus that may have been overlooked by our molecular analysis. To this end, an experiment was designed to reverse the insertion of the $\mathrm{P}[\mathrm{Zw}]$ transposon.

The single $\mathrm{P}[\mathrm{Zw}]$ element in the $\mathrm{M} 1$ strain was mobi- lized in the presence of the P-element transposase. From 35 independent white-eyed viable males recovered, 33 were shown by genetic and Southern analysis to retain various lengths of $\mathrm{P}[\mathrm{Zw}]$ sequences, and only two were indistinguishable from the wild type. The nucleotide sequence of the fragment overlapping the previous $\mathrm{P}[\mathrm{Zw}]$ insertion site was determined for one of them: It was identical to the wild type. These results demonstrate that insertion of the $\mathrm{P}[\mathrm{Zw}]$ element at this site induces the lethality by itself.

The M6 mutant is deleted at its $5^{\prime}$ side from the 8-bp genomic repeat, and 21 of $31 \mathrm{bp}$ of the P-element inverted repeat. Hence, we predicted that this element should not be able to mobilize. In the presence of the $P[\Delta 2-3](99 B)$ source of transposase, neither excision nor autosomal transposition was detected among $>3600$ chromosomes scored.

\section{The enhancer-trap expression pattern}

The lacZ expression pattern was studied during development in heterozygous females and hemizygous males carrying the $\mathrm{Ml}$ chromosome, bearing a single $\mathrm{P}[\mathrm{Zw}]$ element because of a complete and faithful conversion. $\mathrm{X}$-Gal staining was observed in salivary glands, fat body, Malpighian tubules, gut, and brain during the third instar. Very specific traits, such as dotted expression in maxillary palps in late pupae, in agreement with the reduced bristles on palpus (rbp) phenotype (Kiss et al. 1988), and expression in ovarian follicular cells, in agreement with the sterility and egg shell defects observed in some BRC mutants (Mazina et al. 1991; Huang and Orr 1992), were observed (a detailed account will be published elsewhere). Considering what is presently known from molecular studies on the $B R C$ temporal and tissular expression \{Huet et al. 1993; Karim et al. 1993; Emery et al. 1994|, the observed lacZ pattern in convertants can be interpreted as a partial image of the $B R C$ expression. Hence, it can be assumed that in directed conversion, lac $Z$ expression is driven by neighboring genomic controling elements as it is in enhancer trapping.

\section{Discussion}

The genetic nature of the $P[Z w \mid$ convertants and of the original pl 4 allele

The M1 (perfect conversion), M5 (12 bp deleted on 3' side), and M6 (880 bp deleted on the $5^{\prime}$ side) mutants do not complement strong $b r$ and $r b p$ alleles, whereas they complement $2 B C$ alleles. Hence, they define three new $2 B a b$ alleles, which will be named $2 B a b^{8}, 2 B a b^{9}$, and $2 B a b^{10}$, respectively.

The p14 allele was originally classified as a hypomorphic $2 B d$ allele (Belyaeva et al. 1989) or as a weak $2 B c$ allele (Sampedro et al. 1989). Our genetic analysis of the p14 interactions with other $B R C$ alleles disfavors the assumption that it belongs to either the $2 B C$ or the $2 B d$ complementation groups but does not clearly discriminate between the other $B R C$ groups. The three conver- 
tant alleles $2 B a b^{8}$ to $2 B a b^{10}$, due to insertions and deletions at exactly the same site as the p14 P element, exhibit a slight genetic interaction in combination with $p 14$ (Table 1). This led us to classify the $p 14$ mutant as a weak $2 B a b$ allele and, hence, to rename it $2 B a b^{7}$.

Insertions at position 172 of the $B R C$ yield various phenotypic effects, ranging from no effect at all $(\mathrm{P}[\mathrm{Zw}]$ pseudorevertants; see above), no visible phenotype but lack of complementation with a $n p r^{6}$ allele $\left(2 B a b^{7}(p 14)\right)$, to prepupal lethality $\left(2 B a b^{8}\right.$ to $\left.2 B a b^{10}\right)$. Therefore, insertion per se at this position does not yield a $B R C$ mutation. This is in agreement with the fact that the insertion site is located in an intron (DiBello et al. 1991). Still, in $\mathrm{P}[\mathrm{Zw}]$ convertants, the inserted sequences disturb $B R C$ expression. Sampedro et al. (1989) proposed that the lack of complementation observed with the $2 B a b^{7}(p 14)$ allele could result from partial premature termination of $B R C$ transcription at $\mathrm{P}$ sequences. Similarly, taking into account that the P-element transcription-termination signals are weakly efficient (Karess and Rubin 1984), introduction of additional termination signals brought in by the $\mathrm{P}[\mathrm{Zw}]$ element may cause lethality by preventing downstream transcription of the $B R C$ locus. Alternatively, the genetic effect of insertions could be attributable to the introduction of new splice sites. These two hypotheses are not mutually exclusive.

Whatever the actual molecular mechanism may be, it is not clear why the $b r$ and $r b p$ functions are impaired and not the $2 B c$ function because the known promoters and the first (noncoding) exons of the major classes of messages are located upstream of the $\mathrm{P}|\mathrm{Zw}|$ insertion site. The presence of the transposon could preferentially disturb the splicing pattern of the $b r$ and $r b p$ RNA classes (see Fig. 1). Alternatively, it could be assumed that the concentration level of the br and rbp classes of $\mathrm{BRC}$ proteins is more crucial than that of the $2 \mathrm{Bc}$ class.

\section{The mechanism of conversion}

Engels and co-workers (Engels et al. 1990; Gloor et al. 1991), proposed that P-element transposition occurs through a mechanism similar to the repair of radiationinduced double-strand breaks (Resnick 1976), or gene conversion in yeast (Szostak et al. 1983). The transposase would cut both DNA strands of the chromosome, the P element would be excised from its genomic site, and exonucleases present in the nucleus would enlarge the break. Then the gap could be repaired by copying the missing sequences either from the sister chromatid, hence restoring a copy of the original P element, or from the homologous chromosome, yielding a wild-type copy of the genomic sequences (Engels et al. 1990; JohnsonSchlitz and Engels 1993; Nassif and Engels 1993), or even from homologous sequences inserted at an ectopic site of the genome (Gloor et al. 1991; Nassif et al. 1994). This model was supported by genetic experiments from the Engels' group and by the molecular properties of the P-element transposase (Kaufman and Rio 1992). It led to the prediction that it should be possible to introduce dele- tions or insertions by conversion to the excision site, a prediction that has been confirmed (Johnson-Schlitz and Engels 1993; Nassif et al. 1994).

According to Engels' model, it is assumed that the double-strand break occurs at or near the terminal repeats of the $\mathrm{P}$ element, thus initiating transposition. The repair process leading to precise or imprecise excision, and synthesis of a new copy of the transposon or conversion, is primed by use of the homology between the partially degraded strands and the genomic sequences flanking the transposon.

The type of conversion events reported in the present work did not require homology between the donor sequences and the genomic sequences at the converted site: The unique homologous sequences between donor and acceptor sites were located inside and not outside the transposon and were the P-element sequences themselves. Apparently, the simplest way to reconcile our results with Engels' model is to assume that the doublestrand breaks induced by the P-element transposase are internal to the $\mathrm{P}$ element. However, although not excluded, this additional assumption is unnecessary, and the data can well be accounted for by the model, as illustrated in Figure 5. The resolution of the apparent discrepancy is based on the involvement of three templates during the repair process.

Because the $2 B a b^{7}(p 14)$ mutation is viable, the mutagenic males containing both the pl $4 \mathrm{P}$ element and the source of transposase did not need to, and did not, contain an additional copy of the $B R C$ chromosomal region anywhere in the genome. After excision, a repair process leading to conversion could only initiate at $\mathrm{G}_{2}$, after replication, on the sister chromatid. During this repair, the replicating strands copy P-element sequences. At that point, homologous sequences can be found at the ectopic site of the enhancer-trap donor transposon. The conversion process is thus initiated. A second change of partner is needed to resolve the conversion. This will create a mismatch at position 33 of the heteroduplex, illustrated by the two facing noncomplementary A bases on the diagram in Figure 5. This mismatch would be repaired further.

The presence of this polymorphic site allowed us to detect chimeric molecules composed of parts of both the p14 and the $\mathrm{P}[\mathrm{Zw}]$ elements among the convertants. This observation strongly supports the mechanism that we propose. The involvement of three template strands of DNA could well account for certain complex conversion events selected by Gloor et al. (1991). In yeast, plasmidmediated induction of recombination was shown to involve tripartite events between one plasmid and two chromosomes (Silberman and Kupiec 1994).

In addition, the difference between the type of conversion event discussed here and those reported by Engels and co-workers (Engels et al. 1990; Gloor et al. 1991) is similar to ends-in versus ends-out recombination in yeast. In ends-in (O type), the regions of homology between the partners are located on one and the other side of the double-strand cuts; in ends-out ( $\Omega$ type), they are located inside (Hastings et al. 1993). Our results suggest 


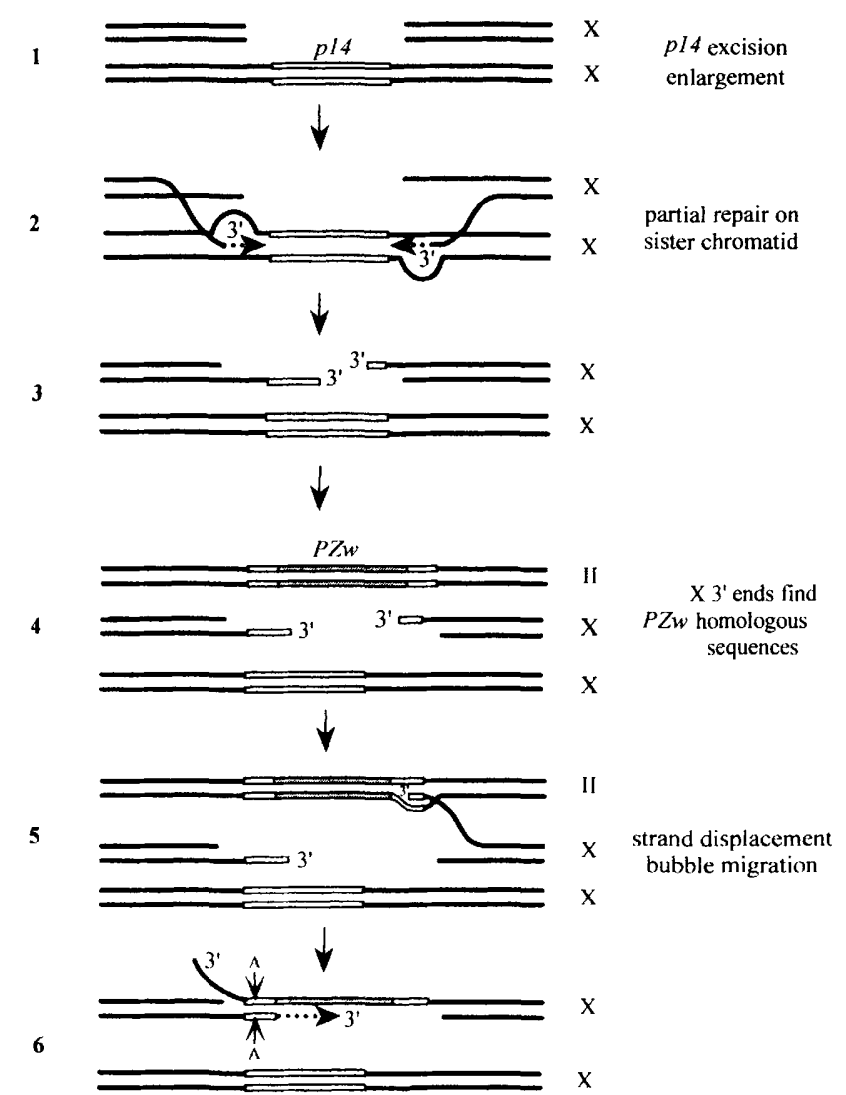

Figure 5. A proposed model for the conversion mechanism. (1) The two sister chromatids of the pl 4 chromosome are represented $(X)$. The p14 P element has been excised from one of the sister chromatids by the action of transposase, and the doublestrand break is enlarged by exonuclease hydrolysis. (2) Gap repair starts first using the genomic and then the pI4 sequences as a template. (3) One or both 3'-replicating ends of the X chromosome leave their sister chromatid template. (4) One (or both) $3^{\prime}$ free ends of the $\mathrm{X}$ chromosome (only one is represented) finds the $\mathrm{P}[\mathrm{Zw}]$ homologous sequences on the second chromosome. The open boxes at the end of the $\mathrm{P}[\mathrm{Zw}]$ and $\mathrm{pl} 14$ element represent homologous sequences. (5) The free $3^{\prime}$ end of the $\mathrm{X}$ chromosome displaces the complementary strand of the second chromosome and pairs with its template. The $3^{\prime}$ end is replicated by use of the $10 \mathrm{~kb}$ of $\mathrm{P}[\mathrm{Zw}]$ as a template and displacing continuously the complementary strand by bubble migration. The replication goes on until it reaches the P-element $5^{\prime}$-end sequences that are homologous with p14 on the $5^{\prime}$ side. (6) The $3^{\prime}$ end of the $\mathrm{X}$ chromosome strand can leave its $\mathrm{P}[\mathrm{Zw})$ template and anneal to the p14 sequences. Exonuclease activity can remove the nonhomologous single-strand tails and repair comes to an end on both $\mathrm{X}$ strands.

that in Drosophila as in yeast, the two $3^{\prime}$-strand invasions are relatively independent.

The fact that all six conversions, perfect and imperfect, were in the same $5^{\prime} \rightarrow 3^{\prime}$ orientation as the original p14 element could indicate that the length of homologous sequences required is longer than the 31-bp inverted terminal repeats, thus forcing one orientation. However, a recent report describes the targeting of a
$\mathrm{P}[\mathrm{Ddc}]$ transposon to a $\mathrm{P}$ element at the vestigial $(\mathrm{vg})$ locus and the recovery, albeit with a lower frequency, of transposons inserted in the opposite orientation (Heslip and Hodgetts 1994). In Drosophila, results indicate that the length of the homology search window would be $<115$ bp (Nassif and Engels 1993). In yeast it has been shown that 63-89 homologous base pairs are the threshold required for copying (Sugawara and Haber 1992). Accumulating data show that the search for homology is a very efficient process. Recently, it was shown that in mammalian cells the search for ectopic homologous sequences does not limit the rate of extrachromosomal recombination (Waldman 1994). In mice, conversions between unlinked hemizygous lac $Z$ transgenes occur spontaneously in the male germ line in $0.1 \%-0.7 \%$ of spermatids (Murti et al. 1994).

The conversion of sequences as long as $10 \mathrm{~kb}$ is not a surprising event. Replication could proceed with the 10 $\mathrm{kb}$ of the $\mathrm{P}[\mathrm{Zw}]$ as a template, continuously displacing the complementary strand by a bubble migration mechanism similar to that described in bacteriophage $\mathrm{T} 4$ (Formosa and Alberts 1986). This kind of mechanism was proposed to account for the efficient copying of nonhomologous sequences from ectopic sites in P-element-induced conversions (Nassif et al. 1994) as well as the preferential P-element transposase-mediated deletions between the long terminal repeats (LTRs) of the copia element (Kurkulos et al. 1994).

The relatively high frequency of conversion events detected, despite the large size of the converted transposon and the presence of a mispairing at position 33 , might have been attributable to the absence of a wild-type copy of genomic sequences, thus driving the repair process toward conversion.

The fidelity of the conversion process (four of six conversion events were precise) could be ensured by degradation of unpaired single-strand tails before ligation, as in yeast (Fishman-Lobell and Haber 1992). The two imperfect conversion events are similar to the well-known imperfect excisions of $P$ elements that may be accompanied by deletion of flanking sequences. They can be accounted for by an imperfect balance between degradation and repair, preventing homologous recognition and resolution of the conversion at the second end of the $P$ element. As already documented, in this case and in other cases of imperfect P-element excisions, very little homology is needed for ligation (O'Hare and Rubin 1983; O'Hare et al. 1992; Lapie et al. 1993). The presence of a $\mathrm{T}$ at position 33 (indicating a $\mathrm{P}\left[\mathrm{Zw}\right.$ ) origin) of the $2 \mathrm{Bab}^{10}$ allele, where an 880-bp genomic deletion is found at the 5 ' end of the conversion, supports this interpretation.

P elements have a trend to transpose within or in close vicinity to pre-existing $\mathrm{P}$ transposons, resulting in double elements of various structures (Roiha et al. 1988; Daniels and Chovnick 1993; Tower et al. 1993; M. Delattre and D. Coen, pers. comm.). It can be visualized that in a first step, a $\mathrm{P}[\mathrm{Zw}$ ] element jumped into (or close to) pl4, creating such a double element, which in a secondary step would give rise, through an intramolecular event, to the replacement of the original pl4 by the 
$\mathrm{P}[\mathrm{Zw}]$ element. However, we did not find any double element at the p14 site.

Replacements of a defective P element at the $\mathrm{vg}$ gene by various $\mathrm{P}[\mathrm{Ddc}]$ and a $\mathrm{P}[\mathrm{Zw}]$ donors were recently reported [Heslip and Hodgetts (1994); Staveley et al. (1994), respectively]. Thus, P-element replacement is not a specific property of either the $\mathrm{P}[\mathrm{Zw}]$ donor or pl4 target element that we used. Previously described P-element transposase-induced events (Salz et al. 1987; Geyer et al. 1988) may also be well accounted for by the present model (Fig. 5).

\section{Perspectives}

The targeted conversion of an unmarked P element by an enhancer-trap transposon at reasonable frequencies opens interesting possibilities. It becomes possible to combine the advantages of the two methods proposed for P-element mutagenesis: shotgun mutagenesis with the Birm2 chromosome containing 17 defective elements (Robertson et al. 1988), and single-copy mutagenesis, with marked elements (Cooley et al. 1989). Shotgun mutagenesis is more efficient in terms of the number of insertions per gamete, allowing PCR screening of an insert in a single gene of interest, (Ballinger and Benzer 1989; Kaiser and Goodwin 1990; Ségalat et al. 1992), whereas the use of engineered elements greatly facilitates localization of the insertion, determination of the pattern of expression by X-gal staining, cloning by plasmid rescue, and the recovery of null mutants by imperfect excision. Similarly, it has been proposed recently to make use of the great variety of P-element inserts available in wild-type Drosophila strains (Clark et al. 1994). The usefulness of this procedure will be greatly improved if, in a second step, wild-type $P$ elements are replaced by enhancer-trap ones.

Given the increasing variety of new P-element-derived tools for Drosophila genetics, such as the FLP/FRT system, the $U A S_{G} / G A L 4$ system, the presence of $O V O^{D 1}$ on autosomes, and the palette of hundreds of $\mathrm{P}$ elements already localized throughout the genome, it would be easier to target one of these newly engineered elements to a site of interest, by use of an outdated, but precisely located, $\mathrm{P}$ element, as a recipient.

Given the complexity and the huge size of the $B R C$, the dissection of its various functions and regulatory sequences could be more amenable to site-directed enhancer trapping than classical transgenesis.

\section{Materials and methods}

Genetic nomenclature

Genetic nomenclature follows Lindsley and Zimm (1992) except that $l(1) 2 B a b, l(1) 2 B c$, and $1(1) 2 B d$ were simplified as $2 B a b$, $2 B c$, and $2 B d$, respectively.

\section{Drosophila stocks}

The original p14 mutant was isolated and kindly provided by I. Zhimulev (Solovyeva and Belyaeva 1989). The $C(1) D X$ y $w \mathrm{f} / \mathrm{w}$
V 1(1)44ts $/ Y$ stock was used to collect virgins (Busson et al. 1983). The $C(1) D X$ y $w f / w$ v $1(1) 44^{t s} / y^{2} Y 67 g 19.1$ was constructed in our laboratory. The rearranged $Y$ chromosome of this stock was provided by I. Zhimulev. The $\mathrm{X}$-transposed fragment extends from $1 \mathrm{Al}$ to $2 \mathrm{~B} 18-19$, thus covering the $B R C$ locus at 2B5 (Belyaeva et al. 1980). The $B R C$ alleles were generously provided by J. Fristrom $\left(b r^{28}, 2 B a b^{5}\right), \mathrm{G}$. Guild $\left(r b p^{4}, r p b^{5}\right.$, $\left.2 B d^{1}\right)$, and I. Zhimulev [Df(1)S39, $\left.n p r^{6}, 2 B c^{1}, 2 B c^{2}\right]$ and are described in Lindsley and Zimm (1992) except for the $b r^{28}$ allele, which corresponds to an insertion of a truncated $P$ element in a coding exon (DiBello et al. 1991) and for the $2 \mathrm{Bab}^{5}$ allele which bears an inversion whose breakpoint separates the promoters from the coding exons (C. Bayer, pers. comm.). The following alleles are considered to be amorphic: $n p r^{6}$ (Belyaeva et al. 1981 ), $2 B c^{1}$ (Kiss et al. 1988), 2BC ${ }^{2}$, (B. Sebban, J. Deutsch, and G. Gonzy-Tréboul, unpubl.), and $b r^{28}, 2 B a b^{5}$ (C. Bayer, pers. comm.). The balancer chromosomes used throughout the crosses were FM6, 1(1)69' (Belyaeva et al. 1980) or Binsn (Lindsley and Zimm 1992). The stable source of transposase was on a $D r, P[\Delta 2-3](99 B)$ chromosome (Robertson et al. 1988). The CyO, $\mathrm{P}[\mathrm{Zw}]$ chromosome was constructed and kindly provided by J.-M. Dura (Laboratoire de Biologie Cellulaire IV; Université Paris-Sud, Orsay, France). The $\mathrm{P}[\mathrm{Zw}]$ element came from mobilization of an enhancer-trap element constructed by E. Bier (Bier et al. 1989). Fly stocks were raised at $20^{\circ} \mathrm{C}$ or $25^{\circ} \mathrm{C}$ and crossed at $25^{\circ} \mathrm{C}$ or $29^{\circ} \mathrm{C}$ on a standard corn meal/sugar/yeast/agar medium.

\section{Genetic screens}

The mating scheme for selecting convertants is described in detail in Results and in Figure 4. Five hundred seventy-four $\mathrm{G}_{0}$

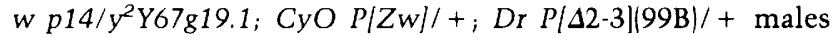
were individually crossed to $C(1) D X$ y $w f / y^{2} Y 67 g 19.1$ females. In 471 crosses, at least one eye-colored, $\mathrm{Cy}^{+}, \mathrm{Dr}^{+}$male appeared, tracing a transposition or conversion event. As many as 544 independent males could be selected from these crosses. This figure is higher than the actual number of favorable crosses, because in some crosses males of various colors appeared. In this case, a representative of each color was picked up. They were kept and qualified as independent only when supported by further genetic analysis. By use of attached $\mathrm{X}$, a simple genetic analysis could discriminate between autosomal and $\mathrm{X}$-linked transposition or conversion. Autosomal lines were discarded. When a double event affected both an autosome and the sex chromosome, the two transposons were separated by segregation. Because only attached $X$ and $X$ balancers were used in our genetic analysis, multiple events affecting only the $X$ chromosome could not segregate. One hundred and fifty-five independent X-linked lines were analyzed.

To mobilize the p14 element $160 \mathrm{G}_{0}$ males carrying the p14 allele on the X chromosome and the $S b, P[\Delta 2-3](99 \mathrm{~B})$ source of transposase on the third chromosome were individually crossed with $C(1) D X$ y $w f / y^{2} Y 67 g 19.1$ females. Ten $G_{1} S b^{+}$males were individually recovered from each cross and were expanded by crossing with the same $C(1) D X$ y $w f / y^{2} Y 67 g 19.1$ females. The crosses were brooded 5 days at $25^{\circ} \mathrm{C}$, after which time the male parents were individually crossed with $C(1) D X$ y $w f / Y$ females to screen for viability. Among 1523 viable males without any BRC phenotype, 50 (progeny of 10 different $G_{0}$ males) were submitted to molecular analysis. Among these, seven (progeny of five different $G_{0}$ males/ could be classified as true revertants because of the precise excision of the p14 element, within the limits of a Southern analysis.

To screen for $2 B a b^{8}(\mathrm{M} 1)$ revertants, a similar experiment was performed: females carrying the novel convertant chromosome, 
that is, $2 B a b^{8} w$ (this work), balanced with $F M 6,1(1) 69^{i}$ were mass-mated to $+/ y^{2} Y 67 g 19.1 ; \operatorname{Dr} P[\Delta 2-3](99 B)$ males. Sixty-five phenotypically $\left(\mathrm{B}^{+}\right.$Dr) $\mathrm{G}_{0}$ males of the offspring were recovered and individually mated with $C(1) D X$ females. Thirty-five independent viable (white $\mathrm{Dr}^{+}$) progeny males were expanded and crossed with $n p r^{6}$ mutant females to test for genetic reversion.

\section{DNA extraction and Southern analysis}

Hemizygous males were collected as wandering third instar larvae. DNA was extracted according to Lapie et al. (1993). Southern blotting was performed according to Sambrook et al. (1989).

\section{Plasmid probes}

The $\mathrm{p} \pi 25.7 \mathrm{bwc}$ plasmid, used as a P-element-specific probe, was kindly provided by $\mathrm{D}$. Anxolabéhère (Institut J. Monod, Paris, France). It bears the HindIII(39)-AvaII(2882) fragment of the $\mathrm{P}$ element and no genomic sequences. The pLBl plasmid was constructed by cloning in a Bluescript vector (Stratagene) a 4.8-kb Sall(170.5)-SalI(176) fragment [coordinates from Chao and Guild (1986)| taken from the P205 BRC clone of the $\lambda$ Charon 4 library kindly provided by I. Zhimulev (Belyaeva et al. 1987). It was used as a $B R C$-specific probe (G probe on Fig. 3). Plasmids were labeled by nick translation (Rigby et al. 1977) to a specific activity of $1 \times 10^{8}$ to $2 \times 10^{8} \mathrm{cpm} / \mu \mathrm{g}$.

\section{In situ hybridization}

In situ hybridization on polytene chromosomes was performed according to Ronsseray et al. (1991) with the p $\pi 25.1$ plasmid as a probe.

\section{Molecular analysis of the $P / Z w /$ conversion mutants}

Cloning by plasmid rescue was performed on MI DNA digested with EcoRI, SacII, PstI, or BglII, according to Pirrotta (1986). Four different plasmids were obtained by this method: pLB27 and pLB28 carried the $3^{\prime}$ junction, pLB29 and pLB30, the $5^{\prime}$ junction.

DNA corresponding to a single fly was amplified in a $20-\mu \mathrm{l}$ volume over 30 cycles with $2 \%$ formamide in the mixture (Sarkar et al. 1990). The sizes of the amplified products were determined from $1.5 \%$ agarose gel electrophoresis by comparing them with products amplified from the pLB27 plasmid (downstream product) or from the pLB29 one (upstream product) with the same pair of primers. Direct sequencing of the PCR products was performed essentially according to Dodé et al. (1990), with $10 \%$ formamide in the sequencing mixture (Zhang et al. 1991).

P-specific primers used for PCR were T1 (89-108), $5^{\prime}$-CGTCCGCACACAACCTTTCC-3', and T2 (2785-2804), 5' -TCGCTGTCTCACTCAGACTC-3'. BRC-specific primers are listed from $5^{\prime}$ to $3^{\prime}$ according to the $B R C$ transcription orientation (see Fig. 3b|. A1, 5'-GTATGTGTGCCACATTGCGC-3'; A2, 5' -GC-

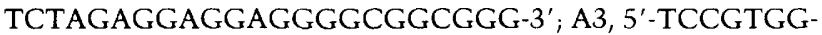
AGGGATAGGAACC-3'; A4, 5'-CCAATGTGCCAGCATGCCCC-3'; and A5, 5'-CTGCGCCCAGAATCGATGCG3'.

$B R C$ primers $\mathrm{A} 1, \mathrm{~A} 2$, and $\mathrm{A} 5$, were used for amplification; $\mathrm{A} 3$ and $A 4$ for the subsequent sequencing. The size of the pl4 element was estimated by amplification with a single primer complementary to the P-element terminal repeats (positions 3-31).

\section{Histochemical staining}

Third-instar larvae were staged on standard corn meal medium containing $0.05 \%$ bromophenol blue. $\beta$-Galactosidase activity was tested in larvae and pupae according to Lemaitre and Coen (1991) and in adult ovaries according to Lemaitre et al. (1993).

\section{Acknowledgments}

We thank the students of the Module de Dynamique du Génome de l'Université Pierre et Marie Curie for their help in genetic screening, C. Rigolot for her technical assistance in sequencing, and P. Feynerol and K. Taalba for their help in maintaining fly stocks. We are very grateful to C. Bayer, I. Fristrom, I. Emery, and G. Guild for sharing results before publication, to G. Guild, C. Bayer, and I. Zhimulev for sending DNAs, to I. Zhimulev and E. Belyeva, C. Bayer, J. Fristrom, and G. Guild for sending fly stocks and to C. Bayer, D. Coen, M. Delattre, and F. Schweisguth for stimulating discussions and suggestions. We are particularly grateful to J. Haber, J.-L. Rossignol, F. Schweisguth, and A. Kropfinger for their reading and comments on the manuscript, with special thanks to Cindy Bayer. This work was supported by the CNRS and grant 6294 from the Association pour la Recherche sur le Cancer to J.-A. L.

The publication costs of this article were defrayed in part by payment of page charges. This article must therefore be hereby marked "advertisement" in accordance with 18 USC section 1734 solely to indicate this fact.

\section{References}

Andres, A.J. and C.S. Thummel. 1992. Hormones, puffs and flies: The molecular control of metamorphosis by ccdysone. Trends Genet. 8: 132-138.

Ashburner, M., C. Chihara, P. Meltzer, and G. Richards. 1974. Temporal control of puffing activity in polytenc chromosomes. Cold Spring Harbor Symp. Quant. Biol. 38: 655-662.

Ballinger, D.G. and S. Benzer. 1989. Targeted gene mutations in Drosophila. Proc. Natl. Acad. Sci. 86: 9402-9406.

Belyaeva, E.S., M.G. Aizenzon, V.F. Semeshin, I. Kiss, K. Koczka, E.M. Baricheva, T.D. Gorelova, and I.F. Zhimulev. 1980. Cytogenetic analysis of the 2B3-4-2B11 region of $\mathrm{X}$ chromosome of Drosophila melanogaster, I: Cytology of the region and mutant complementation groups. Chromosoma 81: 281-306.

Belyaeva, E.S., I.E. Vlassova, Z.M. Biyasheva, V.T. Kakpakov, G. Richards, and I.F. Zhimulev. 1981. Cytogenetic analysis of the 2B3-4-2B1l region of the $\mathrm{X}$ chromosome of Drosophila melanogaster. II. Changes in the $20-\mathrm{OH}$ ecdysone puffing caused by genetic defects of puff $2 \mathrm{~B} 5$. Chromosoma 84: 207219.

Belyaeva, E.S., M.O. Protopopov, E.M. Baricheva, V.F. Semeshin, M.L. Izquierdo, and I.F. Zhimulev. 1987. Cytogenetic analysis of the $2 \mathrm{~B} 3-4-2 \mathrm{~B} 11$ region of the $\mathrm{X}$ chromosome of Drosophila melanogaster, VI: Molecular and cytological mapping of the ecs locus and the $2 \mathrm{~B}$ puff. Chromosoma 95: 295-310.

Belyaeva, E.S., M.O. Protopopov, E.B. Dubrovsky, and I.F. Zhimulev. 1989. Cytogenetic analysis of ecdysteroid action. In Ecdysone: From chemistry to mode of action led. J. Koolman|, pp. 368-376. Georg Thieme Verlag, Stuttgart, Germany.

Bier, E., H. Vaessin, S. Sheperd, K. Lee, K. McCall, S. Barbel, L. Ackerman, R. Carretto, T. Uemura, E. Grell, L.Y. Jan, and Y.N. Jan. 1989. Searching for pattern and mutation in the Drosophila genome with a P-lacZ vector. Genes \& Dev. 3: 1273-1287.

Busson, D., M. Gans, K. Komotopoulou, and M. Masson. 1983. Genetic analysis of three dominant female sterile mutations 
located on the X chromosome of Drosophila melanogaster. Genetics 105: 309-325.

Chao, A.T. and G.M. Guild. 1986. Molecular analysis of the ecdysterone-inducible 2B "early" puff in Drosophila melanogaster. $E M B O$ /. 5: 143-150.

Clark, A.G., S. Silveria, W. Meyers, and C.H. Langley. 1994. Nature screen: An efficient method for screening natural populations of Drosophila for targeted P-element insertions. Proc. Natl. Acad. Sci. 91: 719-722.

Cooley, L., C. Berg, R. Kelley, D. McKearin, and A. Spradling. 1989. Identification and cloning Drosophila genes by single P element insertional mutagenesis. Prog. Nucleic Acids Res. 36: 99-109.

Daniels, S.B. and A. Chovnick. 1993. P-Element transposition in Drosophila melanogaster-an analysis of sister-chromatid pairs and the formation of intragenic secondary insertions during meiosis. Genetics 133: 623-636.

DiBello, P.R., D.A. Withers, C.A. Bayer, J.W. Fristrom, and G.M. Guild. 1991. The Drosophila Broad-Complex encodes a family of related, zinc finger proteins. Genetics 129: 385-397.

Dodé, C., J. Rochette, and R. Krishnamoorthy. 1990. Locus assignment of human $\alpha$ globin by selective amplification and direct sequencing. Br. J. Haematol. 76: 275-281.

Emery, I.F., V. Bedian, and G.M. Guild. 1994. Differential expression of the Broad-Complex transcription factors may forecast tissue-specific developmental fates during Drosophila metamorphosis. Development 120: 3275-3287.

Engels, W.R., D.M. Johnson-Schlitz, W.B. Eggleston, and J. Sved. 1990. High-frequency P element loss in Drosophila is homolog dependent. Cell 62: 515-525.

Engels, W.R., C.R. Preston, and D.M. Johnson-Schlitz. 1994. Long-range cis preference in DNA homology search over the length of a Drosophila chromosome. Science 263: 16231625.

Fauvarque, M.O. and J.M. Dura. 1993. polyhomeotic regulatory sequences induce developmental regulator-dependent variegation and targeted P-element insertions in Drosophila. Genes \& Dev. 7: 1508-1520.

Fishman-Lobell, J. and J.E. Haber. 1992. Removal of non-homologous DNA ends in double-strand break recombination: The role of the yeast ultraviolet repair gene RAD1. Science 258: $480-484$.

Formosa, T. and B.M. Alberts. 1986. DNA synthesis dependent on genetic recombination: Characterization of a reaction catalyzed by purified bacteriophage $\mathrm{T} 4$ proteins. Cell 47: 793-806

Geyer, P.K., K.L. Richardson, V.G. Corces, and M.M. Green. 1988. Genetic instability in Drosophila melanogaster: P-element mutagenesis by gene conversion. Proc. Natl. Acad. Sci. 85: 6455-6459.

Gloor, G.B., N.A. Nassif, D.M. Johnson-Schlitz, C.R. Preston, and W.R. Engels. 1991. Targeted gene replacement in Drosophila via P element-induced gap repair. Science 253: 11101117.

Hama, C., Z. Ali, and T.B. Kornberg. 1990. Region-specific recombination and expression are directed by portions of the Drosophila engrailed promoter. Genes \& Dev. 4: 1079-1093.

Hastings, P.J., C. McGill, B. Shafer, and J.N. Strathern. 1993. Ends-in vs. ends-out recombination in yeast. Genetics 135: 973-980.

Heslip, T.R. and R.B. Hodgetts. 1994. Targeted transposition at the vestigial locus of Drosophila melanogaster. Genetics 138: $1127-1135$.

Huang, R.Y. and W.C. Orr. 1992. Broad-Complex function during oogenesis in Drosophila melanogaster. Dev. Genet. 13: $277-288$.
Huet, F., C. Ruiz, and G. Richards. 1993. Puffs and PCR: The in vivo dynamics of early gene expression during ecdysone responses in Drosophila. Development 118: 613-627.

Johnson-Schlitz, D.M. and W.R. Engels. 1993. P-element-induced interallelic gene conversion of insertions and deletions in Drosophila melanogaster. Mol. Cell. Biol. 13: 70067018.

Kaiser, K. and S.F. Goodwin. 1990. "Site-selected" transposon mutagenesis of Drosophila. Proc. Natl. Acad. Sci. 87: 16861690.

Karess, R.E. and G.M. Rubin. 1984. Analysis of P transposable element function in Drosophila. Cell 38: 135-146.

Karim, F.D., G.M. Guild, and C.S. Thummel. 1993. The Drosophila Broad-Complex plays a key regulatory role in controlling ecdysone-regulated gene expression at the onset of metamorphosis. Development 118: 977-988.

Kaufman, P.D. and D.C. Rio. 1992. P-element transposition in vitro proceeds by a cut-and-paste mechanism and uses GTP as a cofactor. Cell 69: 27-39.

Kiss, I., A.H. Beaton, J. Tardiff, D. Fristrom, and J.W. Fristrom. 1988. Interactions and developmental effects of mutations in the Broad-Complex of Drosophila melanogaster. Genetics 118: $247-259$

Kurkulos, M., J.M. Weinberg, D. Roy, and S.M. Mount. 1994. P-element mediated in vivo deletion analysis of white-apricot: Deletions between direct repeats are strongly favored. Genetics 136: 1001-1011.

Lapie, P., F. Nasr, J.A. Lepesant, and J. Deutsch. 1993. Deletion scanning of the regulatory sequences of the $F b p 1$ gene of $D$. melanogaster using $\mathrm{P}$ transposase-induced deficiencies. $\mathrm{Ge}$ netics 135: 801-816.

Lemaitre, B. and D. Coen. 1991. P regulatory products repress in vivo the $\mathrm{P}$ promoter activity in $\mathrm{P}-\mathrm{lacZ}$ fusion genes. Proc. Natl. Acad. Sci. 88: 4419-4423.

Lemaitre, B., S. Ronsseray, and D. Coen. 1993. Maternal repression of the P-element promoter in the germline of Drosophila melanogaster - a model for the $P$ cytotype. Genetics 135: 149-160.

Lindsley, D.L. and G. Zimm. 1992. The genome of Drosophila melanogaster. Academic Press, San Diego, CA.

Mazina, O., E.S. Belyaeva, and I.F. Zhimulev. 1991. Cytogenetical analysis of the $2 \mathrm{~B} 3-4-2 \mathrm{~B} 11$ region of the $\mathrm{X}$ chromosome of Drosophila melanogaster. VII: Influence of the ecs locus on female fertility. Mol. Gen. Genet. 225: 99-105.

Murti, J.R., M. Bumbulis, and J.C. Schimenti. 1994. Gene conversion between unlinked sequences in the germline of mice. Genetics 137: 837-843.

Nassif, N. and W. Engels. 1993. DNA homology requirements for mitotic gap repair in Drosophila. Proc. Natl. Acad. Sci. 90: $1262-1266$.

Nassif, N., J. Penney, S. Pal, W.R. Engels, and G.B. Gloor. 1994. Efficient copying of nonhomologous sequences from ectopic sites via P-element-induced gap repair. Mol. Cell. Biol. 14: 1613-1625.

$\mathrm{O}^{\prime}$ Hare, K. and G.M. Rubin. 1983. Structures of P transposable elements and their sites of insertion and excision in the Drosophila melanogaster genome. Cell 34: 25-35.

O'Hare, K., A. Driver, S. McGrath, and D.M. Johnson-Schiltz. 1992. Distribution and structure of cloned P-elements from the Drosophila melanogaster P-strain $\pi$. Genet. Res. 60: 3341.

O'Kane, C.J. and W.J. Gehring. 1987. Detection in situ of genomic regulatory elements in Drosophila. Proc. Natl. Acad. Sci. 84: 9123-9127.

Pirrotta, V. 1986. Cloning Drosophila genes. In Drosophila: $A$ practical approach (ed. D.B. Roberts), pp. 83-110. IRL Press, 
Oxford, UK.

Resnick, M.A. 1976. The repair of double strand breaks in DNA: A model involving recombination. I. Theor. Biol. 59: 97106.

Rigby, P.W.J., M. Diekmann, C. Rhodes, and P. Berg. 1977. Labelling deoxyribonucleic acid to high specificity in vitro by nick translation with DNA polymerase I. $/$. Mol. Biol. 113: 237-251.

Robertson, H.M., C.R. Preston, R.W. Phillis, D.M. JohnsonSchlitz, W.K. Benz, and W.R. Engels. 1988. A stable genomic source of $\mathrm{P}$ element transposase in Drosophila melanogaster. Genetics 118: 461-470.

Roiha, H., G.M. Rubin, and K. O'Hare. 1988. P element insertions and rearrangements at the singed locus of Drosophila melanogaster. Genetics 119: 75-83.

Ronsseray, S., M. Lehmann, and D. Anxolabéhère. 1991. The maternally inherited regulation of P elements in Drosophila melanogaster can be elicited by two copies at cytological site $1 \mathrm{~A}$ on the X chromosome. Genetics 129: 501-512.

Rubin, G.M. and A.C. Spradling. 1982. Genetic transformation of Drosophila with transposable element vectors. Science 218: 348-353.

- 1983. Vectors for P element-mediated gene transfer in Drosophila. Nucleic Acids Res. 11: 6341-6351.

Salz, H.K., T.W. Cline, and P. Schedl. 1987. Functional changes associated with structural alterations induced by mobilization of a P element inserted in the sex-lethal gene of Drosophila. Genetics 117: 221-231.

Sambrook, I., F.F. Fritsch, and T. Maniatis. 1989. Molecular cloning: A laboratory manual. Cold Spring Harbor Laboratory Press, Cold Spring Harbor, New York.

Sampedro, J., J. Galceran, and M. Izquierdo. 1989. Mutation mapping of the 2B5 ecdysone locus in Drosophila melanogaster reveals a long-distance controlling element. Mol. Cell. Biol. 9: 3588-359l.

Sarkar, G., S. Kalpener, and S.S. Sommer. 1990. Formamide can dramatically improve the specificity of PCR. Nucleic Acids Res. 24: 7465.

Ségalat, L., R. Perichon, J.P. Bouly, and J.A. Lepesant. 1992. The Drosophila pourquoi-pas?/wings-down zinc finger protein: Oocyte nucleus localization and embryonic requirement. Genes \& Dev. 6: 1019-1029.

Silberman, R. and M. Kupiec. 1994. Plasmid-mediated induction of recombination in yeast. Genetics 137: 41-48.

Solovyeva, I.V. and E.S. Belyaeva. 1989. Cytogenetic analysis of the region $2 \mathrm{Bl}, 2-2 \mathrm{~B} 9,10$ of the $\mathrm{X}$ chromosome of Drosophila melanogaster. VIII. Genetic analysis of mutations obtained in the system of P-M hybrid dysgenesis. Genetika 25: 12091217.

Staveley, B.E., R.B. Hodgetts, S.L. O'Keefe, and J.B. Bell. 1994. Targeting of an enhancer trap to vestigial. Dev. Biol. 165: 290-293.

Sugawara, N. and J.E. Haber. 1992. Characterization of doublestrand break-induced recombination: Homology requirements and single-stranded DNA formation. Mol. Cell. Biol. 12: $563-575$.

Szostak, J.W., T.L. Orr-Weaver, and R.J. Rothstein. 1983. The double strand repair model for recombination. Cell 33: 2535.

Tower, J., G.H. Karpen, N. Craig, and A.C. Spradling. 1993. Preferential transposition of Drosophila $P$ elements to nearby chromosomal sites. Genetics 133: 347-359.

Waldman, A.S. 1994. The search for homology does not limit the rate of extrachromosomal homologous recombination in mammalian cells. Genetics 136: 597-605.

Wilson, C., H.J. Bellen, and W.J. Gehring. 1990. Position effects on eucaryotic gene expression. Annu. Rev. Cell Biol. 6: 679714.

Zhang, W., G. Hu, and A. Deisseroth. 1991. Improvement of PCR sequencing by formamide. Nucleic Acids Res. 19: 6649. 


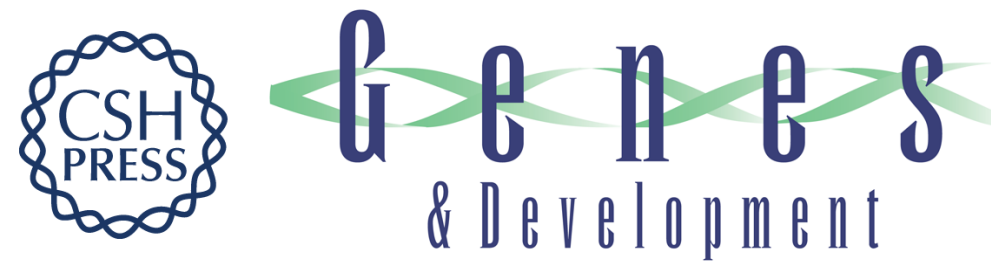

\section{Enhancer-trap targeting at the Broad-Complex locus of Drosophila melanogaster.}

G Gonzy-Tréboul, J A Lepesant and J Deutsch

Genes Dev. 1995, 9:

Access the most recent version at doi:10.1101/gad.9.9.1137

References This article cites 64 articles, 40 of which can be accessed free at:

http://genesdev.cshlp.org/content/9/9/1137.full.html\#ref-list-1

License

Email Alerting

Service

Receive free email alerts when new articles cite this article - sign up in the box at the top right corner of the article or click here.

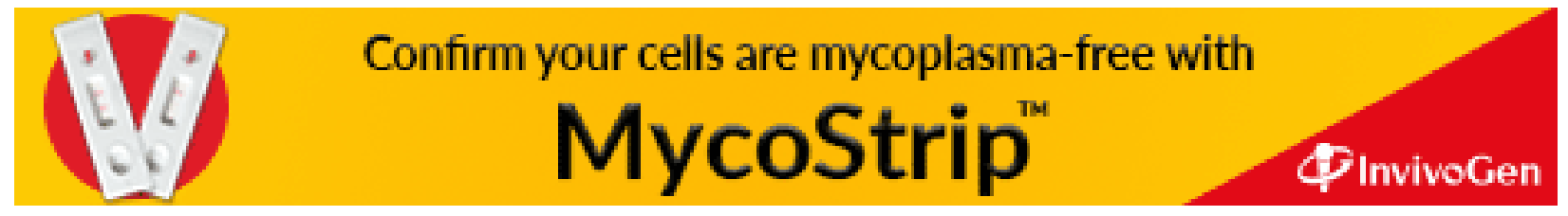

